\title{
Bullying Behavior Among School Children in South India
}

\author{
Samir Kumar Praharaj, MBBs, MD, DPM*; Praveen A. Jain, M.Phil; Avinash Kamath, MBBs, MD; \\ Podila S.V.N. Sharma, MBBS, MD, DPM \\ Department of Psychiatry, Kasturba Medical College, Manipal, Manipal Academy of Higher Education, Karnataka, India
}

\section{Introduction}

- Bullying is common in school-aged youth which affects well-being ${ }^{1,2}$

- Victims of bullies have a variety of mental and somatic health problems ${ }^{3}$

- The frequency of any form of bullying ranged from $15 \%$ to $70 \%$ across countries ${ }^{1,2}$

- Indian data from schools found rates varying from $31 \%$ to $60 \%{ }^{4}$

- Several forms of bullying including verbal, physical and psychological forms are described ${ }^{1,2,5}$

- Physical aggression is more commonly reported among boys, whereas, indirect forms of bullying is more common among girls ${ }^{1,2}$

- The objective was to study the bullying pattern in a large cohort of school going children in South India

\section{Methods}

- Cross-sectional, observational survey

- Part of Eurasian Child Mental Health Study (EACMHS) across 13 countries

- Indian sample - 2016 sixth to ninth graders from 11 schools of Udupi district of South India

- Bullying was assessed as part of the survey, using an instrument developed by Nansel et al..$^{5}$ questions on being exposed to or participating in bullying, specific type of victimization and perpetrator identity

- Informed consent from parents and assent from children obtained

- Survey was done in the class with help of teachers

- Anonymity and confidentiality ensured

\section{Results}

- Mean age was 13.4 (SD 0.9) years

- $979(48.6 \%)$ were boys

- Grade $6(68,3.4 \%), 7(299,14.8 \%), 8$ $(711,35.3 \%), 9(938,46.5 \%)$

- 1919 (95.2\%) were living with biological parents, $61(3 \%)$ with mothers, $9(0.4 \%)$ with fathers, $4(0.2)$ with adoptive parents, $22(1.1)$ with others

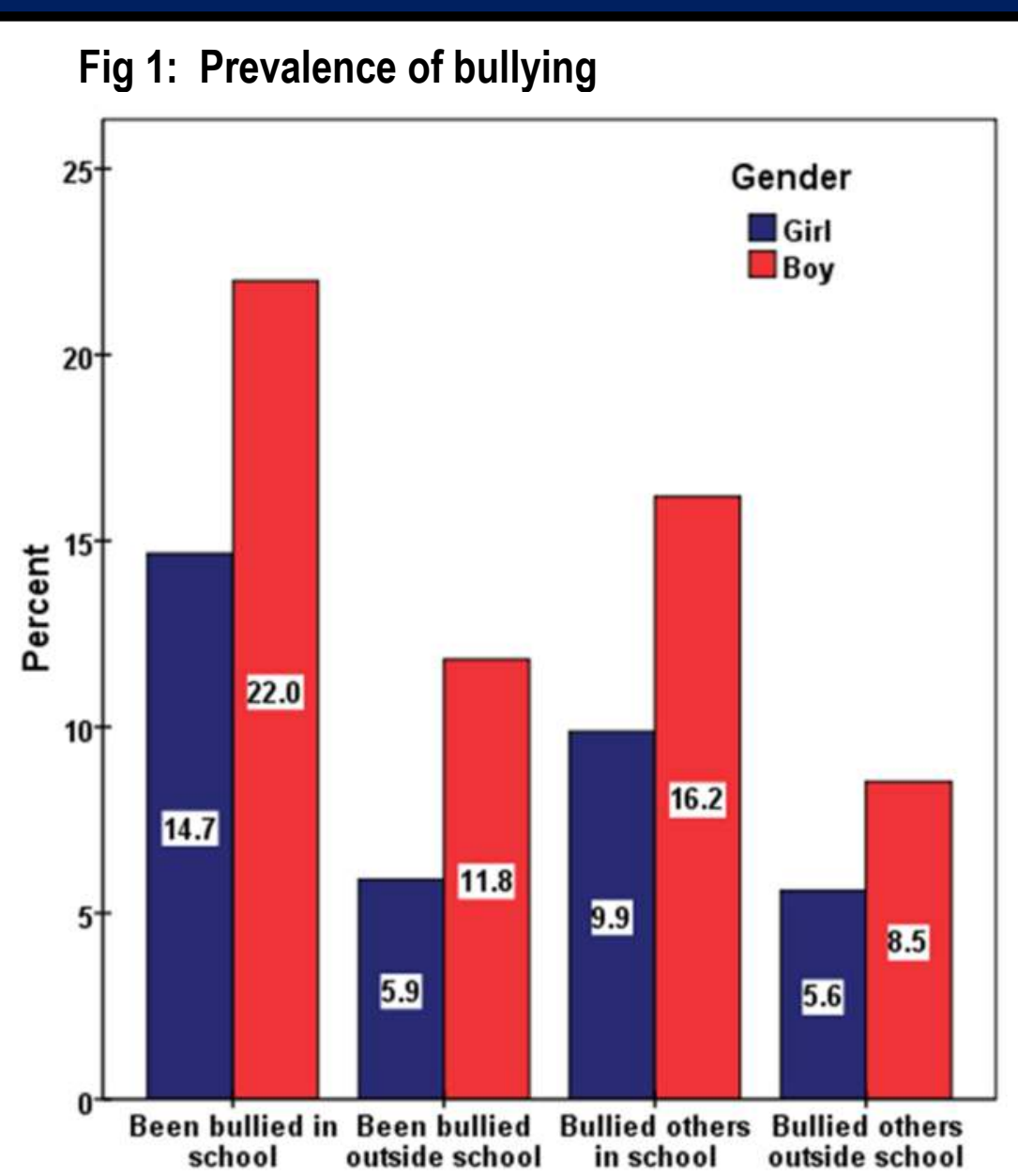

- The prevalence of bullying was $21.7 \%$ $(95 \% \mathrm{Cl} 19.9-23.6 \%)$ in the sample

$(419 / 1932)$

- The prevalence of bullies was $15.7 \%(95 \%$

Cl $14.2-17.4 \%)$ in the sample (302/1919)

Fig 2: Bullying characteristics

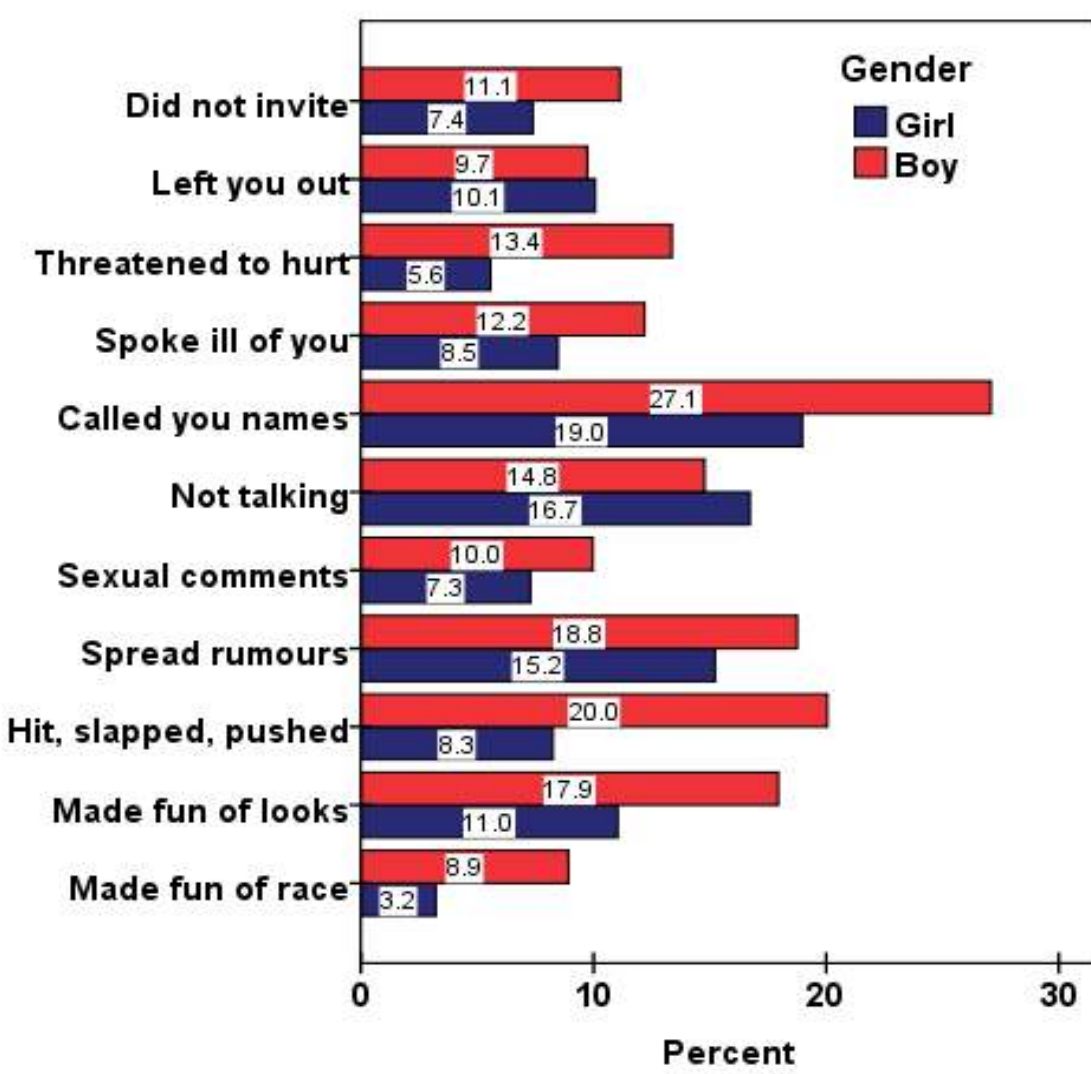

- Boys have higher odds of being bullied in school (OR 1.7, 95\% Cl 1.3-2.1, p<.0001) or outside school (OR 2.3, 95\% Cl 1.6-3.2, $p<.0001)$

- The most common form of bullying was calling names (23.5\%), spreading rumors $(17.2 \%)$, not talking $(16.7 \%)$ and making fun because of looks (15.4\%)

- Physical aggression was seen in $14.9 \%$ and sexual comments in $9.7 \%$

- $14.4 \%$ of girls reported being bullied by girls as compared to $7.3 \%$ of boys ( $p<.001)$, whereas, $27.9 \%$ of boys reported being bullied by boys as compared to $9.7 \%$ of girls $(p<.001)$

\section{Discussion}

- Prevalence of bullying behavior is similar to other studies, but there is a wide variation in prevalence ${ }^{1,2}$

- The rates are lower than previous studies from India (53\% in Chandigarh, $60 \%$ in Davangere $)^{4,6}$

- Developed countries (Norway, Finland) that have strong antibullying programs have lower rates of bullying ${ }^{1-3}$

- Bullying behavior is more common among boys, consistent with previous studies and reflects the dominance strategy 1,2,4,5

- However, bully victims were predominantly boys in our sample, in contrast to higher rates among girls ${ }^{2}$

- Name calling is the most common form of bullying behavior and was higher among boys ${ }^{1,5}$

- Almost all forms of bullying were more common among boys, which is consistent across studies ${ }^{2}$

- Verbal (threatening) and physical (hit or push) aggression was more prevalent among boys, a stereotypical pattern seen in other studies ${ }^{1,2}$

- Limitation include nonrandom sample and predominance of private schools, thus limiting generalizability

- A nationwide representative study is needed to examine the patterns of bullying across the states

- Bullying intervention is required to reduce the prevalence of bullying as well as the possible psychological consequences among bully victims

\section{Highlights}

- Bullying is widely prevalent among school children in South India (22\%)

- Boys are more likely to be victims as well as perpetrators as compared to girls

- Psychological forms were more common than physical aggression

- "Same-gender bullying" was more common than opposite gender bullying

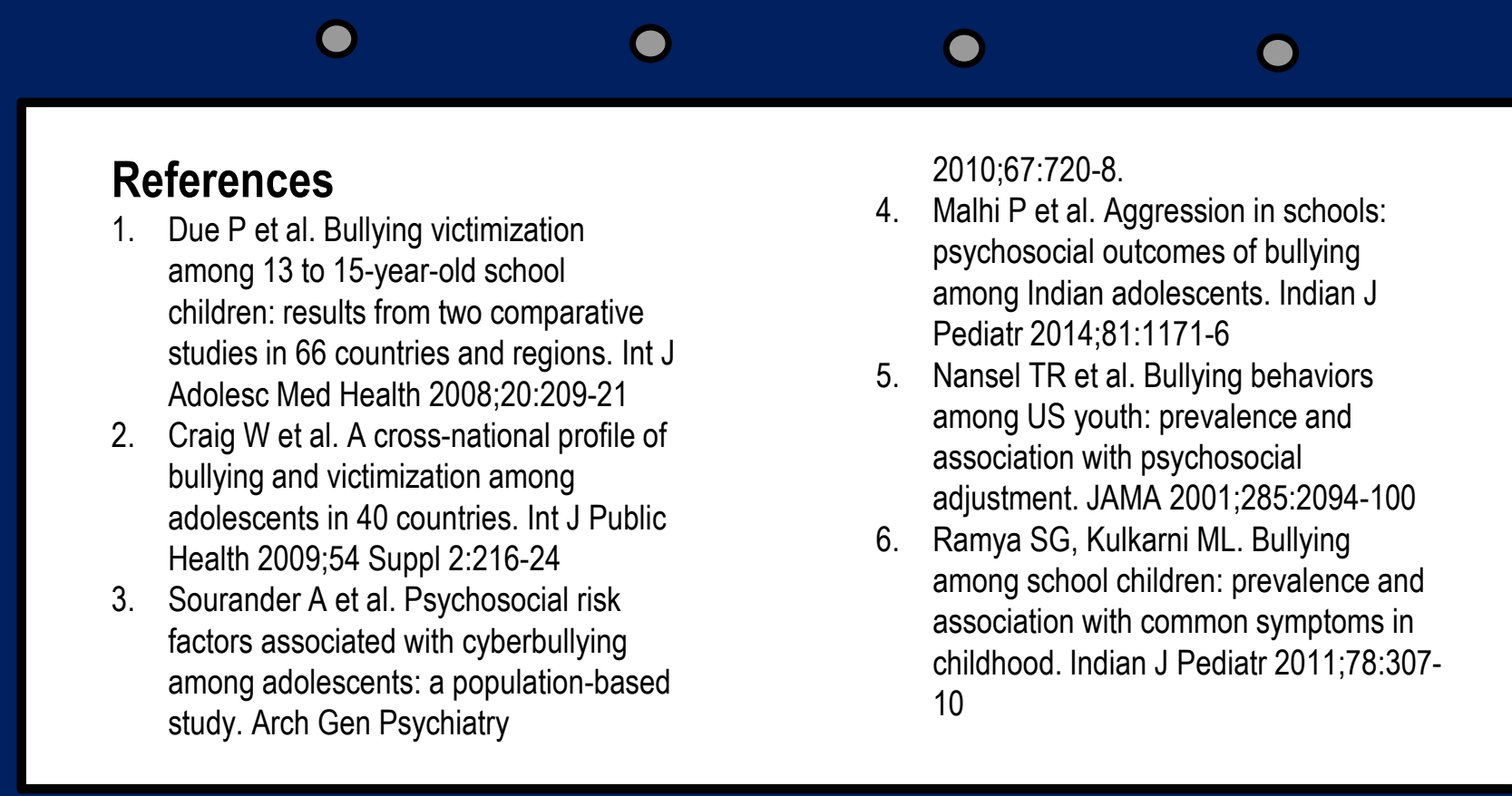

